\title{
Complement Inhibitors in Clinical Trials for Glomerular Diseases
}

\author{
Peter F. Zipfel ${ }^{1,2 *}$, Thorsten Wiech ${ }^{3}$, Ramona Rudnick ${ }^{1}$, Sara Afonso ${ }^{1 \dagger}$, Fermin Person ${ }^{3 t}$ \\ and Christine Skerka ${ }^{1}$ \\ ${ }^{1}$ Department of Infection Biology, Leibniz Institute for Natural Product Research and Infection Biology, Jena, Germany, \\ ${ }^{2}$ Friedrich-Schiller-University, Jena, Germany, ${ }^{3}$ Institute of Pathology, University Hospital Hamburg-Eppendorf, Hamburg, \\ Germany
}

Defective complement action is a cause of several human glomerular diseases including atypical hemolytic uremic syndrome (aHUS), anti-neutrophil cytoplasmic antibody mediated vasculitis (ANCA), C3 glomerulopathy, IgA nephropathy, immune complex membranoproliferative glomerulonephritis, ischemic reperfusion injury, lupus nephritis, membranous nephropathy, and chronic transplant mediated glomerulopathy. Here we summarize ongoing clinical trials of complement inhibitors in nine glomerular diseases and show which inhibitors are used in trials for these renal disorders (http://clinicaltrials.gov).

Keywords: inhibitors, clinical trials, glomerular disease, C3 glomerulopathy, complement, ANCA, aHUS

\section{INTRODUCTION}

Defective complement action is a cause of several human glomerular diseases including atypical hemolytic uremic syndrome (aHUS), anti-neutrophil cytoplasmic antibody mediated vasculitis (ANCA), C3 glomerulopathy, IgA nephropathy, immune complex membranoproliferative glomerulonephritis, renal ischemic reperfusion injury, lupus nephritis, membranous nephropathy, and chronic transplant mediated glomerulopathy $(1-3)$.

Pathology of these kidney disorders are caused or modified by (i) genetic alterations in complement genes that lead to impaired protein expression and/or function (4), (ii) by autoantibodies that target complement components or regulators, (iii) by autoantibodies which recognize specific surface structures, DNA and IgGs, and upon binding initiate complement or (iv) as recently shown by altered plasma levels of FHR-modulators (5). Understanding how the gene variants deregulate complement, or how disease relevant autoantibodies interfere in the cascade help to understand the underlying pathomechanisms of these renal disorders and allow to pinpoint for each disease which step and which level of the cascade is compromised or modified. This provides a rationale for treatment with complement inhibitors (5), and allows to address the questions, where and at which level the complement cascade should be targeted and for how long a complement inhibitor should be used.

The complement inhibitors Eculizumab (Soliris), Berinert, or Cinryze are currently approved by the Food and Drug administration (FDA) in the US and the European Medicines Agency (EMA). A new generation of complement inhibitors is currently evaluated in clinical trials and new inhibitors are being developed and tested in preclinical settings. Different types of inhibitors exist, including humanized monoclonal antibodies, small proteins binding to specific complement components, and furthermore recombinant proteins allowing substitution of defective or absent proteins, as well as a small interfering RNA. 
Here we summarize the ongoing clinical trials of complement inhibitors in nine glomerular diseases and show which inhibitors are used in trials for these renal disorders (http://clinicaltrials.gov).

\section{COMPLEMENT: INITIATION, MAJOR ENZYMATIC CHECK POINTS, AND MULTIPLE EFFECTOR LEVELS}

To appreciate the many steps of complement activation and the fine balanced regulation an overview of this important homeostatic system is presented. The complement cascade has three activation routes, acts via two major enzymatic levels, which provide central checkpoints for the control of effector response and initiate the pore forming terminal complex (Figure 1). Overactive effector pathways drive and enhance specific responses that cause kidney pathology (6). The progression of each step and specific activation pathways are regulated by selectively acting endogenous inhibitors and this control provides the rational to where and at which level activation and pathway progression can be influenced by therapeutic agents.

Initial spontaneous activation of the complement cascade by the alternative pathway (AP) occurs in the fluid phase, activation proceeds and propels on surfaces. The lectin (LP) and the classical pathway (CP) are initiated on target surfaces by different recognition and initiator proteins $(7,8)$. Upon activation two central enzymatic levels are formed, both of which cleave a soluble complement compounds $\mathrm{C} 3, \mathrm{C} 4$, and $\mathrm{C} 5$, and generate small, soluble and cell attracting inflammatory mediators, i.e., C3a, C4a, and C5a and also form the surface acting effector compounds, C3b, C4b, and C5b. The first enzymatic level is mediated by two newly formed C3 convertases with overlapping activity (9). Both the AP and the LP/CP convertase (C3bBb and $\mathrm{C} 4 \mathrm{bC} 2 \mathrm{~b}$, respectively) cleave the central complement protein $\mathrm{C} 3$ and generate the soluble inflammatory mediator $\mathrm{C} 3 \mathrm{a}$ and surface acting $\mathrm{C} 3 \mathrm{~b}$ which opsonizes target surfaces (10). In addition this level can generate a potent, self-amplifying loop which enhances and propels $\mathrm{C} 3$ conversion, generates more effector products and thereby increases the density of deposited C3b can subsequently be processed by specific proteases which are assisted by cofactors and regulators. The processed variants, iC $3 \mathrm{~b}, \mathrm{C} 3 \mathrm{dg}$, or $\mathrm{C} 3 \mathrm{~d}$ are recognized by different receptors and mediate important effector functions (6).

Subsequently when activation proceeds a second enzymatic level is formed. Two C5 convertases, i.e., the AP pathway ( $\mathrm{C} 3 \mathrm{bBbC} 3 \mathrm{~b})$ and the LP/CP pathway $(\mathrm{C} 4 \mathrm{bC} 2 \mathrm{bC} 3 \mathrm{~b})$ convertases, which use $\mathrm{C} 5$ as substrate are generated. C5 cleavage produces the potent soluble anaphylatoxin $\mathrm{C} 5 \mathrm{a}$ and $\mathrm{C} 5 \mathrm{~b}$ is deposited on the target surface (10). Surface deposited C5b initiates the third major effector part and forms the pore forming terminal complex C5ab-9, also termed TCC (terminal complement complex), which inserts in the target membrane, forms a pore and causes cell lysis (Figure 1).

Thus, complement when activated generates several effectors. The major and primary soluble effectors are the anaphylatoxins
C3a, C5a, and C4a that by recruiting and activating immune cells, induce complement inflammation. Recently PAR1 (proteaseactivated receptor) and PAR4 were identified as non G-coupled receptors for $\mathrm{C} 4 \mathrm{a}$ and a FHR1 receptor in form of EMR1 was reported $(11,12)$. The major surface acting effectors are $\mathrm{C} 3 \mathrm{~b}$, the C3- and the C5 convertases and C5b-9. C3b deposition results in opsonophagocytosis and C5b-9 deposition induces the pore forming, membrane damaging C5b-9 complex, and soluble C5b-9 likely has pro-inflammatory activity $(1,2)$.

Complement action can initiate in the fluid phase and on surfaces and a large panel of regulators controls cascade progression at many sites and in specific steps. Regulators which are distributed in the fluid phase or are expressed on cellular surfaces control initiation of each activation pathway, formation and action of the $\mathrm{C} 3$ convertases, density and type of deposited $\mathrm{C} 3 \mathrm{~b}$, the fate of $\mathrm{C} 3 \mathrm{~b}$, formation and action of the $\mathrm{C} 5$ convertase, fate and half-life of the anaphylatoxins and formation of the terminal complement complex.

An important challenge is to understand complement regulation, define how the activators and the many regulators cooperate with each other, understand which inhibitor acts at which site and furthermore how and when the absence of one single regulator, or a single defective regulator affects the concerted action and disturbs the cascade. Understanding of the homeostatic role of this evolutionary old system, and characterizing the precise action of each single regulator and their interplay is highly relevant to elucidate the pathological principles of complement associated disorders. This ultimately allows to design precisely acting complement targeting therapeutic agents.

\section{DISEASES}

\section{Hemolytic Uremic Syndrome (HUS)}

HUS, hemolytic syndrome (HUS) is characterized by an over activated complement system. This disease which has different triggers is defined by hemolytic anemia, thrombocytopenia and acute renal damage resulting in thrombotic microangiopathy (TMA). The majority of HUS cases are caused by infections, with enterohemorrhagic, shiga toxin producing Escherichia coli (EHEC), inducing Shigatoxin HUS. Similarly, infections with Streptococcus pneumoniae can cause pneumococcal HUS. HUS induced by infections is more frequent in children $(13,14)$.

Genetic alterations and autoantibodies cause very similar or even the same clinical symptoms. Genetic-atypical HUS, accounts for about $15 \%$ of total HUS cases and is more frequent in adults. About $60-70 \%$ of these patients have genetic defects in one or several genes, which include nine complement genes (1517) and a gene coding for a cytoplasmic signaling protein (18). The affected genes encode proteins, that (i) form the alternative pathway $\mathrm{C} 3$ convertase (C3, Factor B), (ii) regulate the activity of this central complement enzyme (Factor H, MCP/CD46, Factor I), (iii) act as complement modulators (FHR1, FHR3, FHR4, thrombomodulin) (18), or (iv) the cytoplasmic signaling protein (DAGKe) (19). This puts local AP C3-convertase induced complement and $\mathrm{C} 3$ regulation in the focus of genetic aHUS 


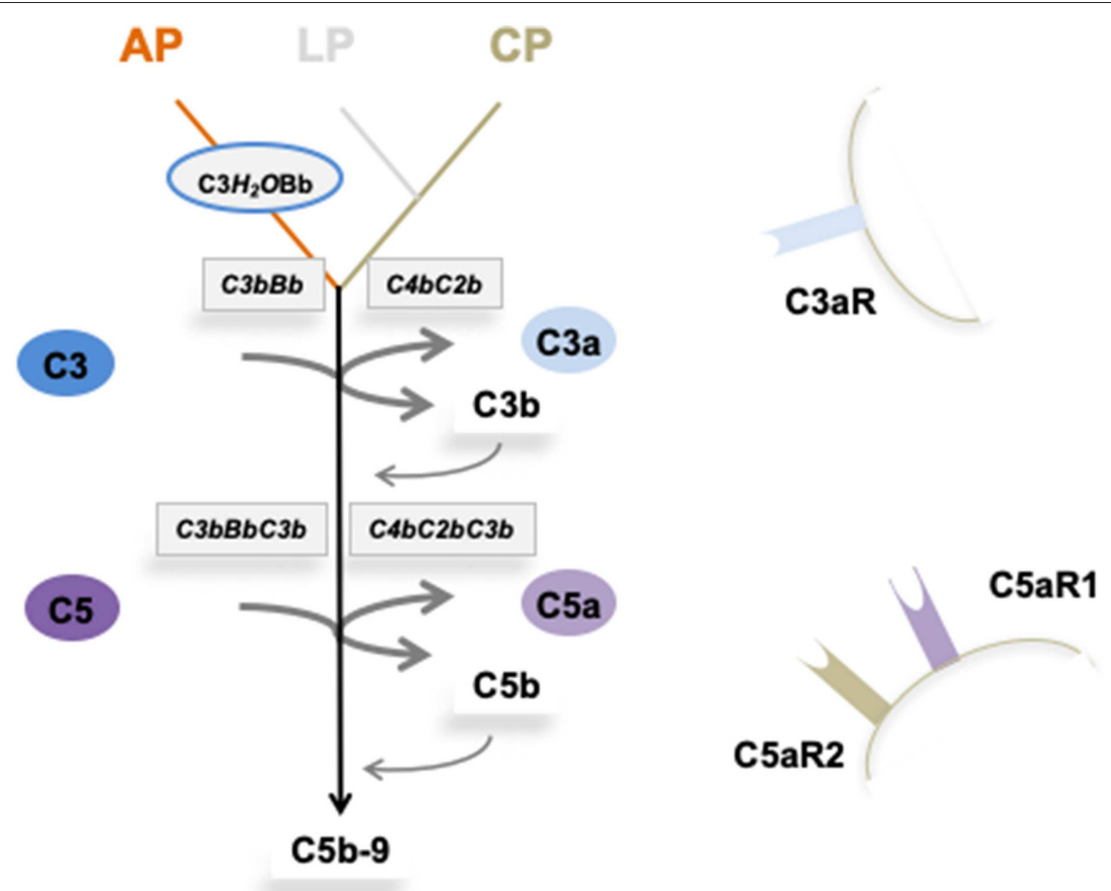

Soluble component

C3b Surface bound component

FIGURE 1 | Overview on complement activation and cascade progression. Complement activation is mediated by the alternative pathway in the fluid phase and on surfaces, and by the lectin and the classical pathway on surfaces. Multiple regulators determine and adjust cascade progression and subsequence effector action. Thereby discriminating the action between intact self, altered self, and non-self. Three initial reactions activate the complement cascade and have different initial triggers. The alternative pathway (AP) which is initiated spontaneously and continuously in the fluid phase and in the absence of regulators is amplified on surfaces. Both the lectin (LP) and the classical pathway (CP) are initiated on surfaces. The type of surface influences activation and the regulator repertoire decides on cascade progression or inhibition. Different regulators control cascade progression in the fluid phase and on surfaces. The three pathways form surface bound convertases, the AP allows generation of the AP-C3 convertase and the LP/CP trigger CP convertase. The AP C3 convertase also triggers a potent amplification loop. The general role of both C3 convertase is to cleave the abundant plasma protein C3 (concentration 1,000-1,500 $\mu \mathrm{g} / \mathrm{ml}$ ) into the anaphylatoxin C3a and the opsonic C3b. The enzymatic response on the first enzymatic levels is frequently enhanced by the potent self-amplifying amplification loop. If activation C5 convertases are generated and again C5 convertases of the AP and of the LP/CP pathways do exist. The major role of the C5 convertase is to cleave C5 (plasma concentration $350 \mu \mathrm{g} / \mathrm{ml}$ ) into the powerful anaphylatoxin C5a and to generate C5b. Surface bound C5b initiates terminal complement and formation of the terminal complex, C5b-9, also termed membrane attack complex which can form lytic pores. Thus, complement acts on two major enzymatic levels, each of which generates a unique set of effector components with rather diverse functions. The complexity of this cascade is mediated by regulators and inhibitors, which control activation in the fluid phase (AP) and which ensure that activation mainly occurs on non-self surfaces or modified surfaces. In the physiological setting this coordinated action allows to direct the toxic and clearance power to the foreign/modified particles. In case of any dysbalance this action can be targeted toward self-structures and this can cause pathology at specific sites.

mediated pathology and shows the important role of the lytic branch of complement.

An autoimmune form of HUS is observed in about $15 \%$ of HUS patients $(20,21)$. Most autoantibodies have the same binding profile; they bind to the C-terminal recognition region of Factor H (SCRs19-20) and block Factor H surface binding. Most HUS patients with autoantibodies are of young age and have a homozygous deletion of a ca $24 \mathrm{~kb}$ chromosomal segment which encompasses the CFHR3-CFHR1 genes. Therefore, this form is also termed DEAP-HUS patients (DEficient for FHR1-FHR3 and Autoantibody to Factor H Positive).
Due to the over activation of the complement system the endothelial cells of glomerular capillaries are damaged or destroyed (Figures 2A,B) resulting in the formation of the typical microscopic thrombi of acute TMA cases (Figures 2A,C). As a result of multiple thrombus formation in TMA glomerular sclerosis might arise. After a possible resolution of the initial TMA episode, the glomerular capillaries can be remodeled. These activated endothelial cells might synthesize a new glomerular basement membrane (GBM) resulting in a GBM duplication or multilayering, typically found in chronic or relapsing TMA. An overview of typical histological 

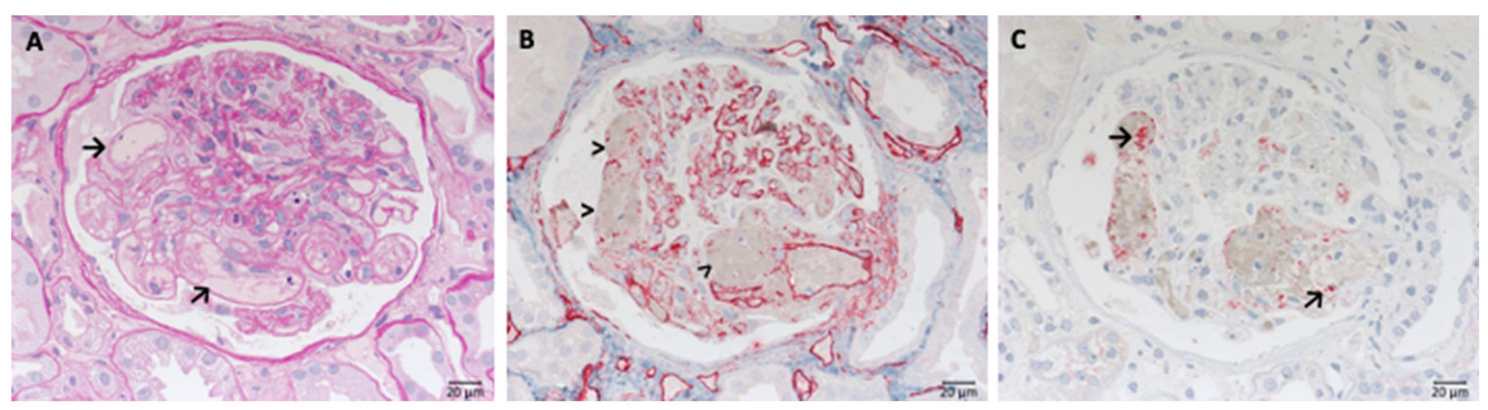

FIGURE 2 | Morphological changes in atypical uremic hemolytic syndrome (aHUS) resulting in thrombotic microangiopathy (TMA). (A) Periodic acid Schiff (PAS) reaction: focal loss of endothelial cells and fibrin precipitates in dilated glomerular capillaries $(\rightarrow)$. (B) Loss of CD34-positive endothelial cells stained red ( $>$ ). (C) Accumulation of platelets stained red in CD61 immunohistochemistry $(\rightarrow)$.

features of genetic aHUS induced acute TMA is displayed in Figure 2.

Genetic aHUS is a prime example of a complement mediated disease and the terminal complement inhibitors Soliris/Eculizimab is already approved and on the market for therapy. This monoclonal antibody binds to C5, blocks C5 activation and formation of the terminal complement complex, i.e., C5b-9. Eculizumab was approved for treatment of genetic aHUS by the Food and Drug Administration (FDA) and the European Medicines Agency (EMA) in 2011. Currently a new version of this C5 binding drug is in clinical trials for genetic aHUS. Ravulizumab (or ALXN 1210), is a $\mathrm{pH}$ dependent, C5 binding antibody which releases C5 at low $\mathrm{pH}$. This drug is already approved for PNH (2018) (22-25) (Table 1). For genetic aHUS additional C5 targeting complement inhibitors are evaluated in clinical studies. These include the lectin pathway inhibitor OMS721, which binds and blocks MASP2 action, is evaluated in phase III, coversin, a tick (Ornithodoros moubata) derived C5 inhibitor and CCX168 the C5aR1 antagonist in phase II studies (Table 1). Studies with ALN-CC5 (Cemdisiran), a siRNA which blocks hepatic C5 production were performed, but apparently this trial was withdrawn.

The overall experience with Eculizumab is very good and positive results have been reported for long-term therapy. However, also incomplete inhibitory activities are reported e.g., for patients with C5 mutations (26). It will be of interest to compare how different targeting strategies, e.g., directly targeting $\mathrm{C} 5$, the lectin pathway, or the C5a receptor effector pathway influence the outcome and if genetic aHUS patients with different gene mutations or autoantibodies respond differently to the various inhibitors.

\section{ANCA Associated Glomerulonephritis}

ANCA (anti-neutrophil cytoplasmic antibody-) associated vasculitis (AAV) describes a collection of related disorders, which include granulomatosis with polyangiitis (GPA), microscopic polyangiitis (MPA), and eosinophilic granulomatosis with polyangiitis (EGPA), also called Churg-Strauss syndrome (27). A characteristic feature of these diseases are autoantibodies which cause complement inflammation and cell infiltration in blood vessels and which result in necrosis. The pathological principle of the autoantibodies is targeting neutrophil proteins myeloperoxidase and proteinase 3 . AAV affects approximately 40,000 people in the US and approximately 4,000 new cases are identified each year. In Europe more than 75,000 people are affected and at least 7,500 new cases emerge each year (28).

Complement inflammation triggered by the alternative pathway is associated with ANCA. Autoantibodies induced C5a generation leading to neutrophil infiltration and activation, which initiates a vicious cycle: more neutrophils are attracted to local sites and the activated cells release their granule contents. The damage occurs in small blood vessels, mostly in the kidney but also other organs like lungs, nerves and sinuses can be involved (24).

Because of the damage caused by the degranulation of granulocytes necrosis and subsequent rupture of small vessels arise (Figure 3), particularly inside glomerular tufts. This is followed by proliferation of parietal cells and influx of macrophages, leading to crescent formation, and later segmental (partial) or complete scarring of the affected glomeruli occurs. Due to the almost complete lack of immune deposits inside of the glomeruli the renal manifestation of ANCA associated diseases is frequently called pauci-immune necrotizing glomerulonephritis. However, contrary to the assigned name complement molecules have been detected inside glomeruli affected by AAV in immunohistochemical and mass spectrometry-based studies. The typical picture of a fresh necrosis of glomerular capillaries in AAV is shown in Figure 3.

These pathological aspects make the C5a-C5aR1 axis of particular interest for therapeutic intervention in order to block attraction of neutrophils to local sites, inhibit cell activation and vascular destruction. Ongoing clinical trials approach the inflammatory complement $\mathrm{C} 5 \mathrm{a}-\mathrm{C} 5 \mathrm{a}$ receptor 1 (C5aR1) axis with the soluble C5a peptide binding mAb (IFX-1; InflaRx) in phase II and the C5a receptor antagonist (Avacopan, Chemocentryx) in phase III trials. A clinical trial with Eculizumab was initiated and but enrollment of patients was terminated (Table 1). 
TABLE 1 | Complement inhibitors being evaluated in clinical trials of glomerular diseases

\begin{tabular}{|c|c|c|c|c|c|c|c|c|}
\hline Disease & Inhibitor name & Alternative name & Inhibitor type & Inhibitor target & Company & Phase & Clinical trial code & Comments \\
\hline \multirow[t]{5}{*}{ aHUS } & OMS721 & OMS 00620646 & Antibody & MASP2 & Omeros & III & NCT03205995 & \\
\hline & Eculizumab & Soliris & Antibody & C5 & Alexion & Market & & $\begin{array}{l}\text { NCT02574403; Phase 4, duration of Eculizumab } \\
\text { treatment }\end{array}$ \\
\hline & Ravulizumab & ALXN1210 & $\mathrm{pH}$-dependent Antibody & & Alexion & III & $\begin{array}{l}\text { NCT03131219 } \\
\text { NCT02949128 }\end{array}$ & $\begin{array}{l}\text { Ravulizumab is already approved for paroxysmal } \\
\text { nocturnal haemoglobinuria }\end{array}$ \\
\hline & Coversin (rVA576) & Nomacopan & Peptide & & Akari Therapeutics & III & NCT03829449 & \\
\hline & CCX168 & Avacopan & Small molecule & C5aR1 & ChemoCentryx & $\|$ & NCT02464891 & \\
\hline \multirow[t]{2}{*}{ ANCA-associated vasculitis } & IFX 1 & СaCP 29 & Antibody & C5a & InflaRx & $\|$ & NCT03712345 & Granulomatosis with Polyangitis; Microscopic \\
\hline & CCX168 & Avacopan & Small molecule & C5aR1 & ChemoCentryx & III & NCT02994927 & Polyangintis \\
\hline \multirow[t]{10}{*}{ C3 Glomerulopathy } & OMS721 & OMS 00620646 & Antibody & MASP2 & Omeros & $\|$ & NCT02682407 & DDD \\
\hline & AMY-101 & & Antibody & $\mathrm{C} 3$ & Amyndas & 1 & NCT03316521 & \\
\hline & APL-2 & & Peptide & & Apellis & $\|$ & NCT03453619 & DDD and C3 glomerulonephritis \\
\hline & $\mathrm{ACH} 4471$ & ACH-0144471 & Small molecule & FD & Achillion & $\|$ & NCT03459443 & DDD and C3 glomerulonephritis \\
\hline & & & & & & & NCT03369236 & DDD and C3 glomerulonephritis \\
\hline & & & & & & & NCT03124368 & DDD and C3 glomerulonephritis \\
\hline & LNP023 & & Small molecule & FB & Novartis & $\|$ & NCT03832114 & C3 Glomerulonephritis \\
\hline & Eculizumab & Soliris & Antibody & C5 & Alexion & 1 & NCT01221181 & DDD and C3 glomerulonephritis \\
\hline & & & & & & ॥ & NCT02093533 & C3 glomerulonephritis \\
\hline & CCX168 & Avacopan & Small molecule & C5aR1 & ChemoCentryx & $\|$ & NCT03301467 & DDD and C3 glomerulonephritis \\
\hline \multirow[t]{5}{*}{ IgA nephropathy } & OMS721 & OMS 00620646 & Antibody & MASP2 & Omeros & III & NCT03608033 & \\
\hline & APL-2 & & Peptide & $\mathrm{C} 3$ & Apellis & II & NCT03453619 & \\
\hline & LPNO23 & & Small molecule & Factor B & Novartis & $\|$ & NCT03373461 & \\
\hline & Cemdisiran & ALN-CC5 & RNAi & $\mathrm{C} 5$ & Alnylam & ॥ & NCT03841448 & \\
\hline & CCX168 & Avacopan & Small molecule & C5aR1 & ChemoCentryx & $\|$ & NCT02384317 & \\
\hline $\begin{array}{l}\text { Immune complex } \\
\text { membranoproliferative } \\
\text { glomerulonephritis }\end{array}$ & $\mathrm{ACH} 4471$ & ACH-0144471 & Small molecule & Factor D & Achillion & $\|$ & $\begin{array}{l}\text { NCT03459443 } \\
\text { NCT03124368 }\end{array}$ & \\
\hline Ischemic reperfusion injury & $\mathrm{C} 1 \mathrm{INH}$ & Berinert & Protein & $\mathrm{C} 1 \mathrm{r}$ and $\mathrm{C} 1 \mathrm{~s}$ & CSL Behring & 1 & NCT02134314 & $\begin{array}{l}\mathrm{C} 1 \mathrm{INH} \text { is already approved and on the market for } \\
\text { hereditary angioedema }\end{array}$ \\
\hline \multirow[t]{2}{*}{ Lupus nephritis } & OMS721 & OMS 00620646 & Antibody & MASP2 & Omeros & ॥ & NCT02682407 & \\
\hline & APL-2 & & Peptide & $\mathrm{C} 3$ & Apellis & $\|$ & NCT03453619 & \\
\hline \multirow[t]{2}{*}{ Membranous nephropathy } & OMS721 & OMS 00620646 & Antibody & MASP2 & Omeros & $\|$ & NCT02682407 & \\
\hline & APL-2 & & Peptide & $\mathrm{C} 3$ & Apellis & $\|$ & NCT03453619 & \\
\hline \multirow[t]{6}{*}{ Transplant } & $\mathrm{C} 1 \mathrm{INH}$ & Cinryze & Protein & C1r and $\mathrm{C} 1 \mathrm{~s}$ & Shire & III & NCT02547220 & $\begin{array}{l}\text { Acute Antibody-Mediated Rejection(for patients with } \\
\text { kidney transplant) }\end{array}$ \\
\hline & & Berinert & & & CSL Behring & 1 & NCT02134314 & ESRD \\
\hline & & & & & & & NCT01134510 & Kidney transplant - therapy to prevent organ rejection \\
\hline & AMY-101 & & Antibody & $\mathrm{C} 3$ & Amyndas & 1 & NCT03316521 & \\
\hline & Eculizumab & Soliris & Antibody & C5 & Alexion & $\|$ & NCT02145182 & Prevention of delayed graft function \\
\hline & LFG-316 & Tesidolumab & Antibody & & Novartis & I & NCT02878616 & ESRD \\
\hline
\end{tabular}

Tesidolumab

Antibody

Novartis

NCT02878616

ESRD 


\section{C3 Glomerulopathy With Membranous Nephropathy and Dense Deposits Disease}

C3 glomerulopathy is an umbrella term for a spectrum of related diseases. The diagnosis is primarily based on evaluation of renal biopsies showing prominent immunofluorescent or immunohistochemical staining for C3, which should be two orders of magnitude more intense than staining for immunoglobulins like $\operatorname{IgA}, \operatorname{IgG}$, or $\operatorname{IgM}(29,30)$. The major subtypes of C3 glomerulopathy are C3 dominant membranoproliferative glomerulonephritis (C3 MPGN) (Figure 4) and dense deposit disease (DDD) (Figure 5). DDD is identified by electron microscopy showing thickened glomerular basement membranes with very electron dense material within the membrane and in the mesangium accompanied by mesangial proliferation (31) (Figure 5). Due to historic reasons, DDD is sometimes still referred to as MPGN II. In C3 glomerulopathy cases displaying MPGN patterns, double contours of the

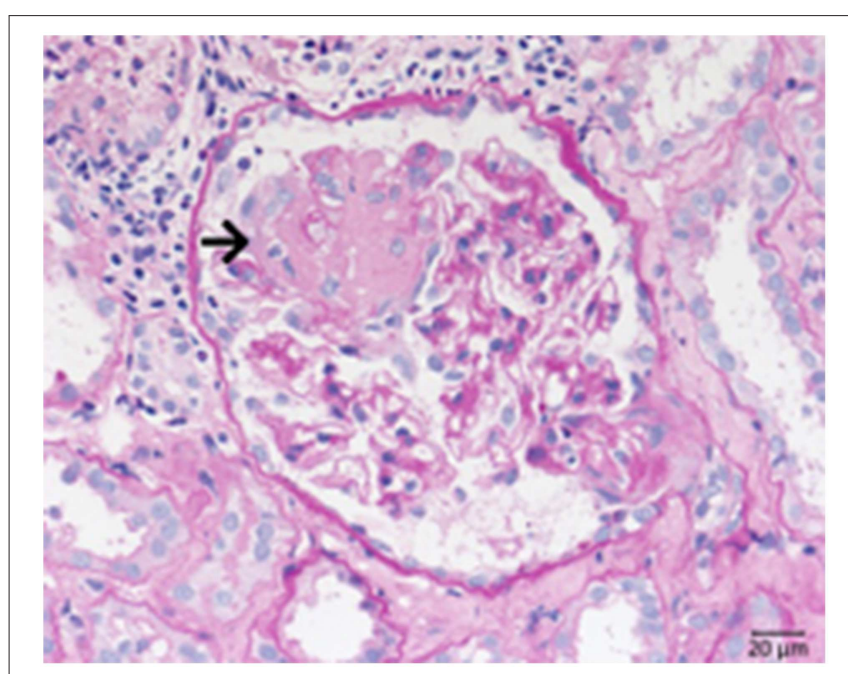

FIGURE 3 | Morphological changes in ANCA associated pauci-immune necrotizing glomerulonephritis. PAS-reaction of a case of ANCA-associated Glomerulonephritis, displaying a rupture of the glomerular basement membrane. See fresh fibrin precipitates inside the bowman space at the side of the necrosis $(\rightarrow)$.
GBM as well as endocapillary and mesangial hypercellularity arises (32) (Figure 5).

C3 glomerulopathy is caused by defective complement regulation with genetic, as well as autoimmune causes. Often defective complement regulation occurs in plasma in the fluid phase and correlates with C3 consumption and low C3 plasma levels. Other forms of this disease develop on basis of normal plasma C3 levels. Genetic causes of C3 glomerulopathy include mutations in the genes coding for Factor $\mathrm{H}, \mathrm{C} 3$, CFHR1, CFHR2, CFHR3, CFHR5, and Factor B. Factor H gene mutations are mostly homozygous or compound heterozygous. In C3 glomerulopathy multiple complex patterns of CFHR gene variations are reported. Alterations include single nucleotide variations in one of the five $C F H R$-gene, and structural variations in the CFHR gene cluster with duplications and deletions of gene elements or of larger chromosomal segments. These genetic alterations generate FHR variant proteins, FHR hybrid proteins and furthermore alter the FHR plasma levels.

Autoimmune factors in C3 glomerulopathy include autoantibodies in form of C3-Nephritic Factor, C4-Nephritic Factor or C5-Nephritic Factor. Most autoantibodies bind to neoepitopes exposed in these central complement enzymes, however some autoantibodies also bind to the single components, i.e., C3, C3b, Factor $\mathrm{H}$ or Factor B. These different autoantibodies show that complement action on the level of the $\mathrm{C} 3$ convertase, as well as $\mathrm{C} 5$ convertase are relevant for this disease spectrum (33-35).

Investigator initiated trials with $\mathrm{C} 5$ targeting by Eculizumab were reported for C3 glomerulopathy. First treatments showed favorable outcome, however studies with large patients cohorts revealed positive effects of Eculizumab in a fraction, about $40 \%$ of the patients, but not in all patients (36-38).

Currently seven complement inhibitors are evaluated in clinical phase I/II trials: OMS721, the MASP2 inhibitor (Omeros), Amy 101 (Amyndas), APL2 a C3 targeting peptide (Apellis), ACH-4471, a Factor D binding antagonist (Achillion), LNP023 a Factor B blocking compound (Novartis), Eculizumab (Alexion), and the $\mathrm{C} 5 \mathrm{a}$ receptor 1 targeting Avacopan (Chemocentryx) (Table 1).

ACH-4771 is a small Factor D inhibitor that is applied orally and that blocks the catalytic side of Factor D. In presence of
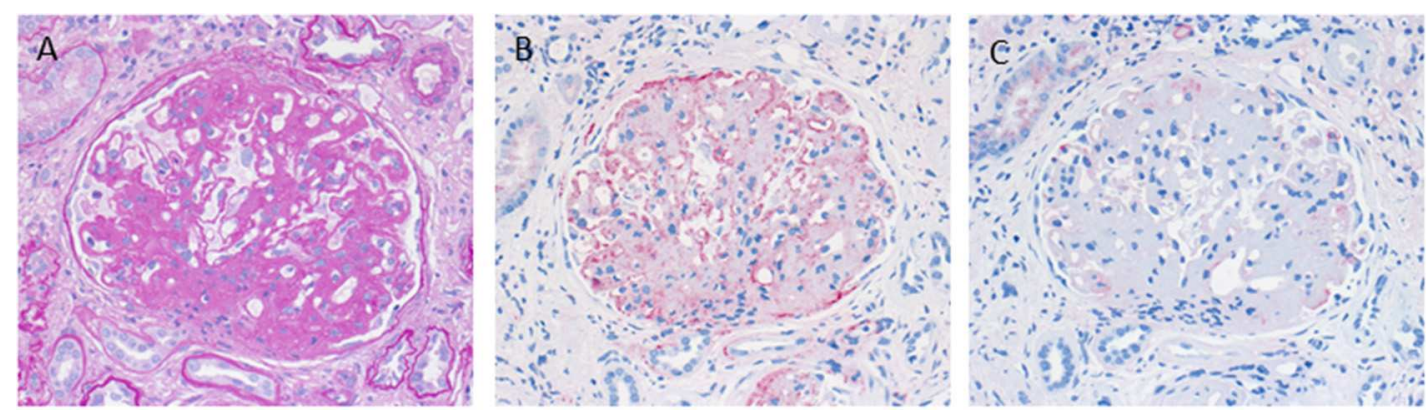

FIGURE 4 | Morphological appearance of C3 glomerulopathy. (A) PAS reaction reveals a membranoproliferative pattern with double contours of the GBM. (B) Strong immunohistochemical positivity for $\mathrm{C} 3$ at the GBM and in the mesangium. (C) Only very scant and segmental positivity for lgG. 

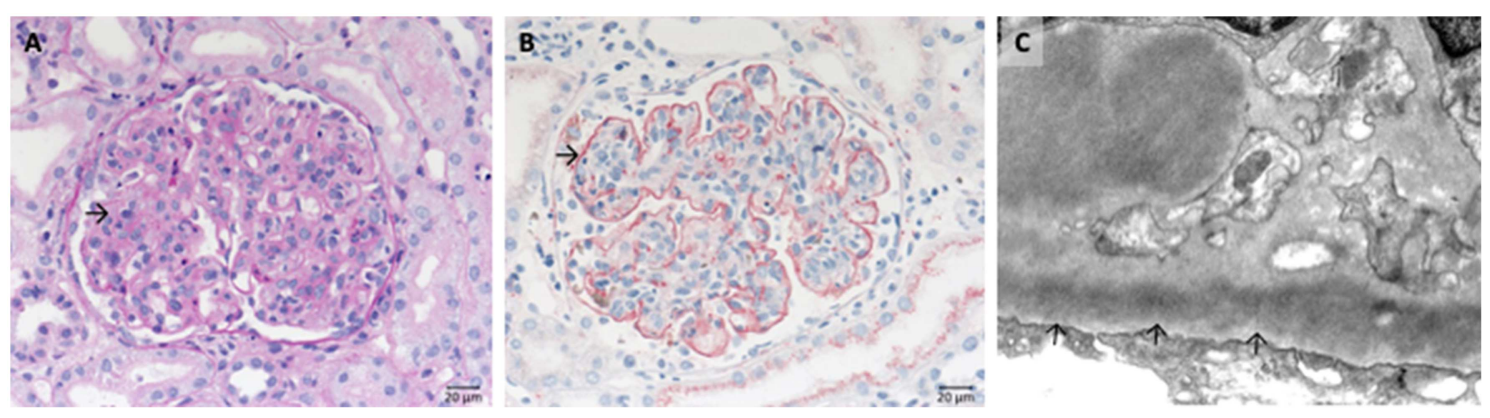

FIGURE 5 | Morphological changes in dense deposit disease (DDD). (A) PAS-reaction of a dense deposit disease case. Note the mesangial and endocapillary hypercellularity without prominent double contours of the glomerular basement membrane $(\rightarrow)$. (B) Note a strong red positivity for C3 inside the glomerular basement membrane $(\rightarrow)$. (C) The name giving electron dense deposits within the thickened glomerular basement membrane $($ GBM, $\rightarrow$ ).

inactive Factor $\mathrm{D}$ the alternative pathway convertase $\mathrm{C} 3 \mathrm{bBb}$, is not formed and complement activation does not proceed. The other orally administered inhibitor LPN023, binds to the active site of Factor B, inhibits the alternative pathway C3 convertase and blocks C3 cleavage. Thus, different inhibitors are currently evaluated which target different levels of the complement cascade, the activation level, the lectin pathway, the C3 convertase of the AP, C3- and C5 cleavage. In this regard, C3 glomerulopathy has the potential to develop to an example for a disease where complement therapy will be approached based on personalized gene or autoimmune profile. Based on the different action sites of the inhibitor, it will be of interest to see which compound or which targeted pathway is most effective and which subform responds or benefits from which inhibitor.

\section{IgA Nephropathy}

IgA nephropathy (IgAN) is a leading cause of chronic kidney diseases with a complex disease pathology and with several factors involved (39). Genome-wide association studies identified the CFHR-gene cluster as a susceptibility locus and opposing effects were reported for individual CFHR genes (40). Homozygous CFHR1/CFHR3-deficiency resulting in the absence of FHR1 and FHR3 in plasma is protective and CFHR5 is an IgAN susceptibility gene (41-44). Rare FHR5 protein variants with altered C3b binding represent risk factors (44). Current work focuses on FHR1- and FHR5-plasma levels $(45,46)$. Elevated FHR1- plasma levels and higher FHR1::Factor H-ratios influence alternative pathway regulation and correlate with disease severity (45-47). In addition also variations of FHR-plasma levels are of pathological relevance (48-50) and enhanced FHR5 plasma levels is an independent risk factor (46). Altered FHR1 and FHR5 plasma levels, or FHR1/Factor $\mathrm{H}$ ratios are disease relevant are related to diseases severity and correlate with alterations in glomerular filtration rates (49-51).

Autoimmune factors include galactose deficient IgA immune complexes or autoantibodies against O-glycans and C3. Genetic and clinic studies link complement and the alternative pathway to immune pathogenesis of IgA nephropathy. But also environmental factors play a role for diseases development. In addition properdin, a complement activator and complement Factor $\mathrm{H}$ are identified in the immune deposits.

IgA nephropathy is marked by the deposition of galactosedeficient IgA1 in the glomerular mesangium (Figure 6A). As a result, mesangial matrix increase and some proliferation of mesangial cells is often seen (Figure 6B), moreover, endocapillary hypercellularity, and eventually rupture of glomerular capillaries with subsequent formation of crescents might occur (extracapillary component). Depending of the severity of the disease glomerular and interstitial injury arises. However, clinical course of IgA nephropathy varies from almost absent clinical symptoms in many cases to fulminant renal failure resulting in dialysis dependent loss of renal function within weeks. Numerous studies suggest that the histological pattern and the deposition of complement components such as $\mathrm{C} 1 \mathrm{q}, \mathrm{C} 3 \mathrm{c}$, and lectin are predictors of worse outcome. The classical appearance of mesangioproliferative IgA nephropathy is depicted in Figure 6.

Clinical studies addressing the complement system in IgA Nephropathy include targeting the MASP-2 by OMS721 (Omeros) (phase III), C3 by APL-2 (Apellis), Factor B by LPN023 (Novartis), C5 by Cemdisiran, and C5aR1 by CCX168 (Chemocentryx) (Table 1).

\section{Immune Complex Membranoproliferative Glomerulonephritis}

Immune complex membranoproliferative glomerulonephritis (MPGN) is marked by dominant deposition of immunoglobulins (Figure 7) and to a lesser extent of complement components inside the mesangium and along the inner side of the GBM. As a result, mesangial, and endocapillary hypercellularity as well as GBM duplication arise (Figure 7B). Additionally, necrosis and crescent formation might occur. Furthermore, in cryoglobulin associated cases hyaline pseudothrombi can be observed inside glomerular capillaries. Several putative causes for the development of immune complex MPGN are known, such as chronic infections, like endocarditis, monoclonal gammopathy, hepatitis $\mathrm{C}$ and the formation of cryoglobulins. An example of the typical histological pattern of immune complex MPGN is displayed in Figure 7. 

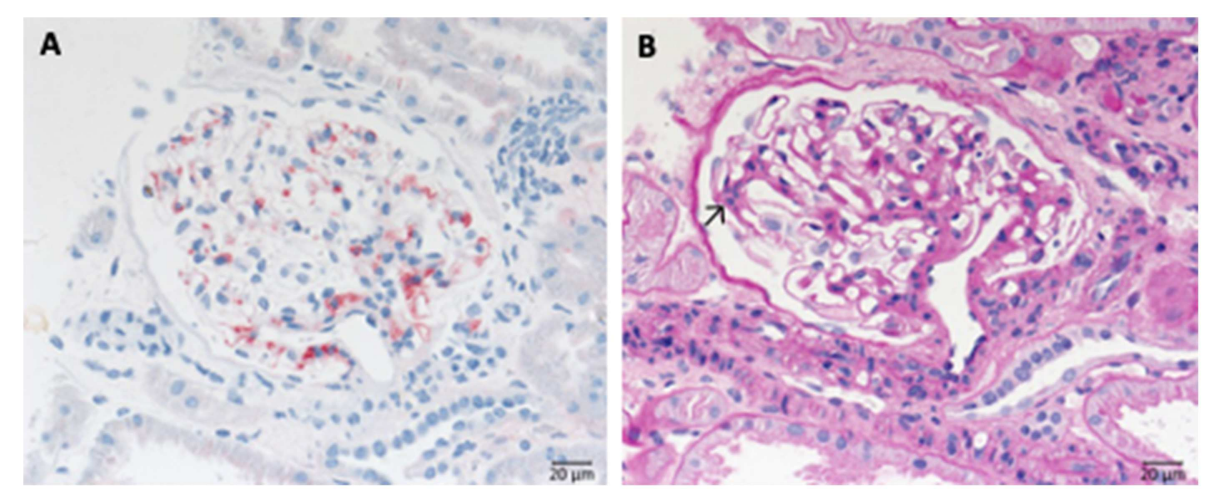

FIGURE 6 | Morphological changes in IgA nephropathy: (A) IgA immunohistochemistry of a case of lgA nephropathy, displaying a noticeable mesangial positivity. (B) PAS reaction of the same glomerulus: note the mesangial matrix increase and the focal mesangial hypercellularity (arrow).
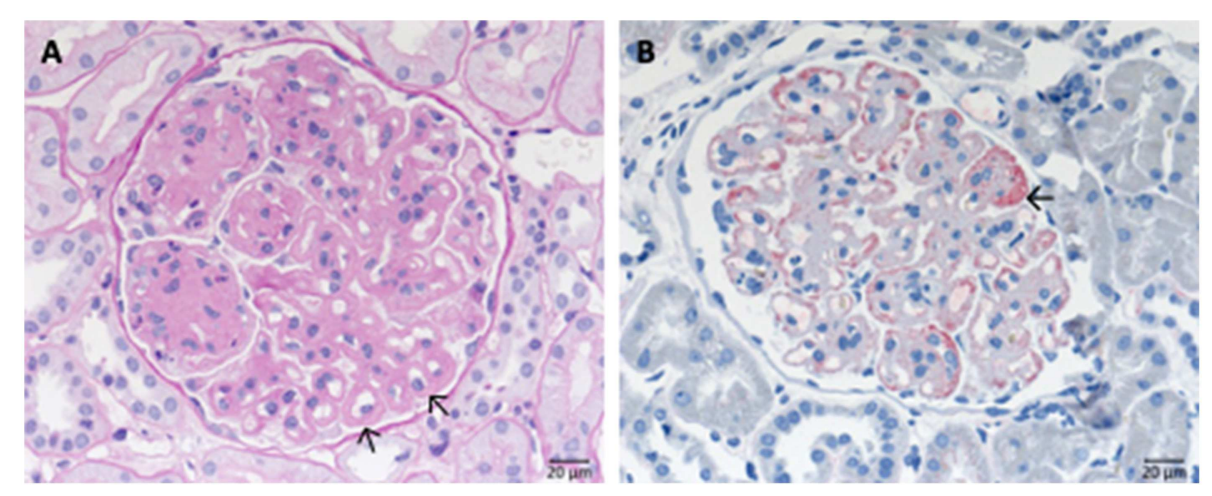

FIGURE 7 | Morphological changes in immune complex membranoproliferative glomerulonephritis (MPGN). (A) PAS-reaction of a case of membranoproliferative glomerulonephritis due to a chronic hepatitis C infection. Note the lobular appearance and double contours of the GBM $(\rightarrow)$. (B) Note positivity for lgG at the side of double contours of the $\operatorname{GBM}(\rightarrow)$.

Clinical trials in Immune complex membranoproliferative Glomerulonephritis are with $\mathrm{ACH} 4471$ (Achillion) in phase II (Table 1).

\section{Lupus Nephritis}

Lupus nephritis is an inflammatory kidney disease occurring in patients suffering from systemic lupus erythematosus (SLE) and active complement is important for the pathogenesis. The classical complement pathway, in particular the components C1, C4, and C2 were for a long time associated with this common form of kidney damage, in particular by defective removal or clearance of damaged self-cells, debris material, and immune complexes. Accumulated self-material initiate complement. In addition a role of the lectin and alternative complement pathway are shown in lupus nephritis $(52,53)$. Inflammatory complement initiated via C5a results in neutrophil infiltration, and autoantibodies to intracellular proteins induce the cascade further.

Systemic lupus erythematosus is an autoimmune disease usually involving multiple organs and as a possible complication the kidneys can be involved. The most important renal consequence of SLE is the development of immune complex glomerulonephritis. However, other possible damage patterns are TMA, interstitial nephritis, podocytopathy, and amyloidosis (Figure 8). SLE associated glomerulonephritis is separated according to the histologic appearance into six different classes (RPS/ISN). Class I lupus nephritis resembles glomerular IgG deposition without further morphological findings at the light microscopic level. Class II shows deposition of immune components, particularly IgG inside the mesangium. A mesangial proliferation is visible by light microscopy. Class III lupus nephritis shows additionally duplication of the GBM and/or endocapillary hypercellularity and/or crescent formation in a minority of the affected glomeruli. Class IV (Figure 8) is characterized by an MPGN like pattern with duplication of the GBM and/or endocapillary hypercellularity and/or crescent formation in the majority of glomeruli. Class V lupus nephritis resembles membranous glomerulonephritis and can occur in combination with any of the other mentioned classes or alone. As an end stage of lupus nephritis class VI is defined as scarring of over $90 \%$ of the sampled glomeruli inside a renal biopsy.

Genetic studies showed that the CFHR1-CFHR3 deletion presents with increased risk for SLE (54). Homozygous deletion of this $24 \mathrm{kbp}$ chromosomal CFHR1-CFHR3 containing fragment 
has kaleidoscope features. First the deletion is common in the healthy population and shows different frequencies in ethnic groups, i.e., being present in ca $30 \%$ of the healthy African, $18 \%$ of the healthy Asian and $5-6 \%$ of the healthy European population (55). Second this homozygous setting confers risk for two renal diseases, SLE and DEAP-HUS and for infections with the pathogenic bacterium Neisseria meningitides. Third the same deletion has protective roles in IgAN, and in the retinal disease Age related macular degeneration (AMD).

In lupus nephritis two phase II clinical trials are ongoing with the complement inhibitors OMS 721 (Omeros) which targets the lectin pathway via MASP2 protein and APL2 (Apellis) which interferes with complement activation at the level of the central complement component C3 (Table 1).

\section{Membranous Nephropathy}

Membranous nephropathy results from binding of IgGs to antigens expressed at the surface of podocytes. Membranous

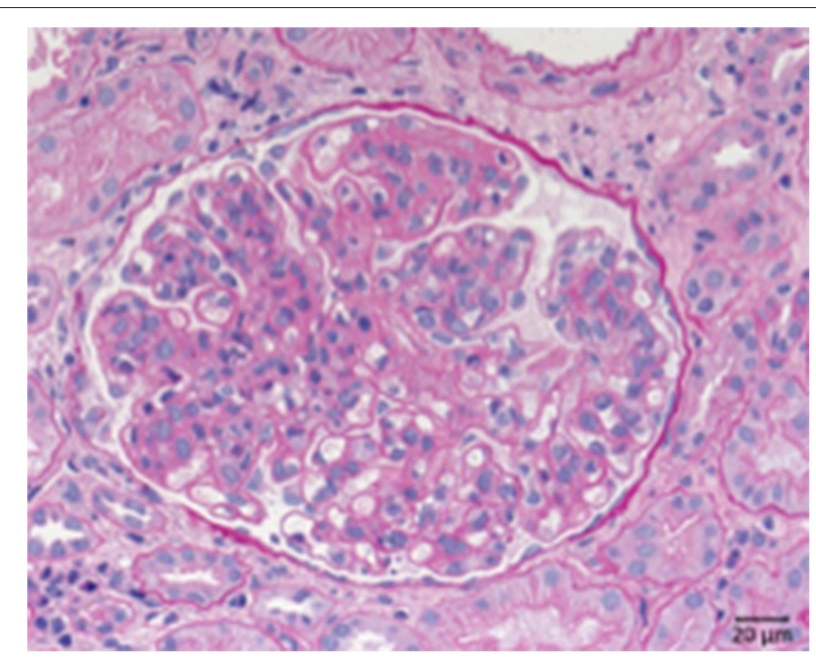

FIGURE 8 | Morphological changes in lupus nephritis, class IV. PAS reaction of a lupus nephritis class IV. Note lobular pattern with pronounced endocapillary and mesangial hypercellularity as well as thickened GBM. nephropathy is grouped into primary cases ( $80 \%$ of cases) without causative autoimmune disease $(56,57)$. In primary membranous nephropathy cases about $70 \%$ show autoantibodies directed against phospholipase $\mathrm{A}_{2}$ receptor $1\left(\mathrm{PLA}_{2} \mathrm{R} 1\right)$, display antibodies directed against thrombospondin type 1 containing 7A (THSD7A) in serum (1-2\%) and to complement Factor $\mathrm{H}(3 \%)$ (57-63). PLA $2 \mathrm{R}$ and THSDA7 are podocyte antigens. The autoantibodies are directed to the receptors exposed on the surface of podocytes. Animal studies show that proteinuria is caused by the terminal complement complex. Also other mechanisms have been proposed.

Also secondary cases (20\% of cases) are known with causative diseases like SLE (Lupus nephritis class V). Complexes formed by the autoimmune IgG and the proper antigen are deposited along the outside of the GBM at the anchoring side of the foot processes of the podocytes (Figure 9).

Most scenarios of primary membranous nephropathy are mediated by autoantibodies to $\mathrm{M}$ type Phosphoplipase $\mathrm{A}_{2}$ receptor $\left(\mathrm{PLA}_{2} \mathrm{R}\right)(95 \%)$ and Thrombospondin type 1 domain containing 7a (THSD7a) receptor, a podocyte antigen (3-5\%). Recently an additional third autoimmune form was described, where autoantibodies developed which target complement Factor H (3\%) (63).

Most PLA 2 R and THSD7A autoantibodies are of the IgG4 subtype, a subtype which does not activate complement, however additional autoantibody forms are identified (56). Components of the classical and the alternative pathways are prominently localized at the site of the IgG-antigen deposits. The IgG-antigen complexes can be found along the outside of the GBM at the anchoring side of the podocyte foot processes (Figure 9B). The GBM expands and overgrows during disease development (Figure 8). Also older deposits inside the GBM are resorbed over longer time periods. As a result foot process retraction arises and nephrotic range proteinuria develops. The typical morphological changes in membranous nephropathy are shown in Figure 9C.

About 3\% of $\mathrm{MN}$ patients have Factor $\mathrm{H}$ binding antibodies which target the $\mathrm{C}$ terminal recognition region of the human regulator and block surface binding (63). In the autoimmune form DEAP-HUS a related pathologic principle,
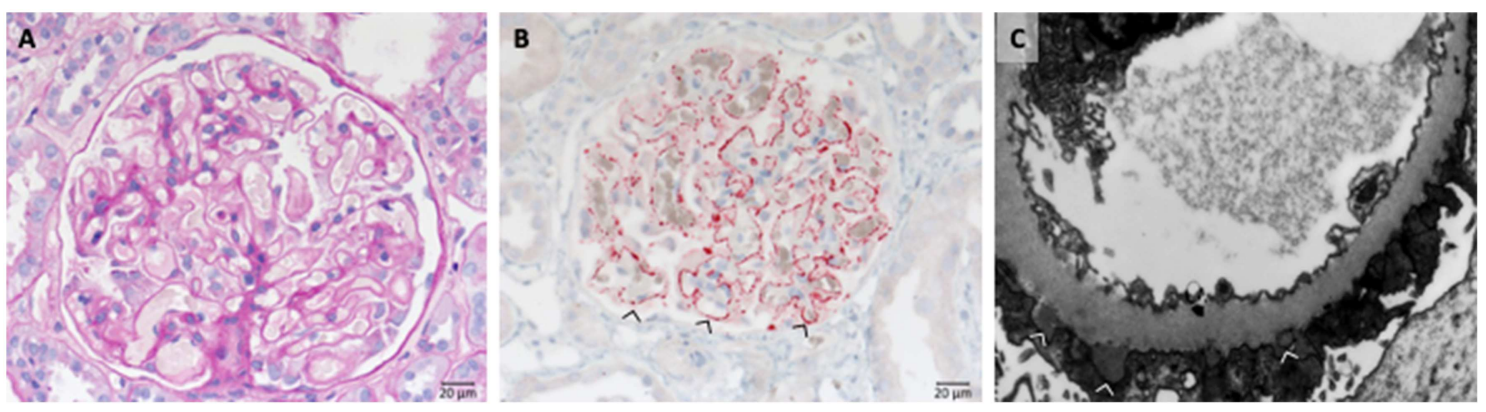

FIGURE 9 | Morphological changes in membranous glomeruloneprhits nephropathy. (A) PAS-reaction with slightly thickened GBM. (B) PLA 2 R1 immunohistochemistry of a PLA ${ }_{2} R 1$-antibody associated case of membranous glomerulopathy. Note strong granular positivity for PLA 21 at the GBM (>). (C) Electron microscopic depiction of subepithelial electron dense deposits (>). 


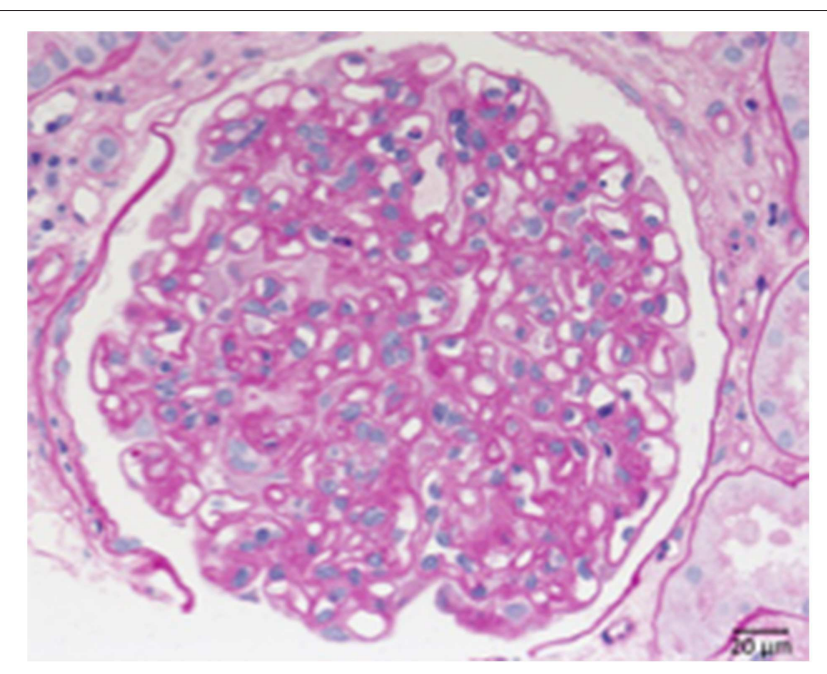

FIGURE 10 | Chronic transplant glomerulopathy. PAS: Chronic transplant glomerulopathy displaying pronounced double contours of the GBM and slight endocapillary hypercellularity.

with autoantibodies targeting the $\mathrm{C}$-terminal binding region Factor H block Factor H surface action $(64,65)$, These features indicate that complement regulation and furthermore cell damage mediated by the terminal complement pathway is a disease relevant mechanisms at the podocyte surface.

Two complement inhibitors OMS 721 (Omeros), which targets the lectin pathway protease MASP2 and APL2 (Apellis), which binds to C3 component, respectively are currently evaluated in clinical trials of membranous nephropathy. Both are in phase II (Table 1).

\section{Renal Transplant}

Complement is activated in transplanted organs and in particular a transplanted kidney can be challenged by activated complement. Numerous approaches are being used to limit complement activation in the transplant in order to block complement inflammation and complement terminal pathway action (66). Involved in renal transplant as the new, foreign surface and under resourced tissue provide a platform for complement activation (67).

Two primary immunological damage mechanisms occurring in transplant kidneys are humoral rejection, with the formation of antibodies against structures of the transplanted organ and cellular rejection with the sensitization of T-cells against donor kidney antigens. The role of the complement system is particularly prominent in cases of humoral rejection. In these cases $\mathrm{C} 4 \mathrm{~d}$, an indicator of acute humoral rejection can be deposited alongside peritubular capillary walls. In case of chronic humoral rejection the steady binding of antibodies leads to the activation or loss of endothelial cells particularly in glomerular and peritubular capillaries. This is followed by the formation of new GBM material (Figure 10). Therefore, a membrane duplication or multilayering of the basement membranes arise in glomerular and peritubular capillaries. The typical morphology of chronic transplant glomerulopathy is displayed in Figure 9.

Different clinical conditions are evaluated in form of acute antibody mediated rejection and also in end stage renal diseases and kidney transplantation to prevent organ rejection. Currently one phase III and two phase I studies are ongoing which evaluate efficacy of the C1 Inhibitors (Cinryze and Berinert). In addition the C5 inhibitor Eculizumab (Alexion) is tested in phase II, and the C5 monoclonal antibody LFG-316 developed by Novartis is tested in a phase I studies (Table 1).

\section{Renal Ischemic Reperfusion Injury}

Ischemic reperfusion injury is a common cause for acute kidney damage which can follow transplantation and which can damage the transplanted organ (68). Acute tubular damage is a common cause for kidney failure and the complement system which is activated on damaged self-cells can propel and increase such local damage (69). Ischemic reperfusion injury is marked by damage to the tubular epithelium. The tubular epithelial cells appear flattened or swollen and the cells suffer a total or partial loss of the brush border.

Complement inhibition in this form of kidney damage is being pursued with the C1 Inhibitor (Table 1).

\section{SUMMARY OUTLOOK}

As outlined here, the current development shows that complement inhibition in renal disease is actively pursued in several clinical studies. Initial proof of concept comes from the inhibitor Soliris/eculizumab which is approved for treatment of genetic aHUS, as well as for two other complement disorders paroxysmal nocturnal hemoglobinuria (PNH) and myasthenia gravis (MG). The expanding list of trials and the increasing number of complement inhibitors, which are being developed and are tested in preclinical studies demonstrate that complement inhibition is an option for therapy of glomerular disorders.

The inhibitors which are tested in clinical trials for glomerular diseases target the activation pathways i.e., the lectin pathway via MASP-2, the central component C3 (APL1 and Amy101), the alternative pathway convertase via Factor D (ACH4471), Factor B (LPN 023), target the terminal pathway via C5 (Eculizumab, LFG-316), by blocking C5 synthesis in the liver via C5-siRNA (Alnylam), or directly interfering with the inflammatory C5aC5aR1 axis (IFX1; InflaRX, and Avacopan; Chemocentryx). Thus, these complement inhibitors target different proteins in different activation pathways or effector levels of complement (Figure 11). This provides the option to block complement at different levels and to interfere with different effector pathways. Given that complement is involved in many renal (and also other) diseases the existing inhibitors allow interfering with complement at different stages.

These inhibitors target complement at different levels and address the various effector pathways. A detailed understanding of the pathological mechanism for each single disease and also of the subforms, combined with an understanding of the mode of action of each inhibitor and a better understanding of the 


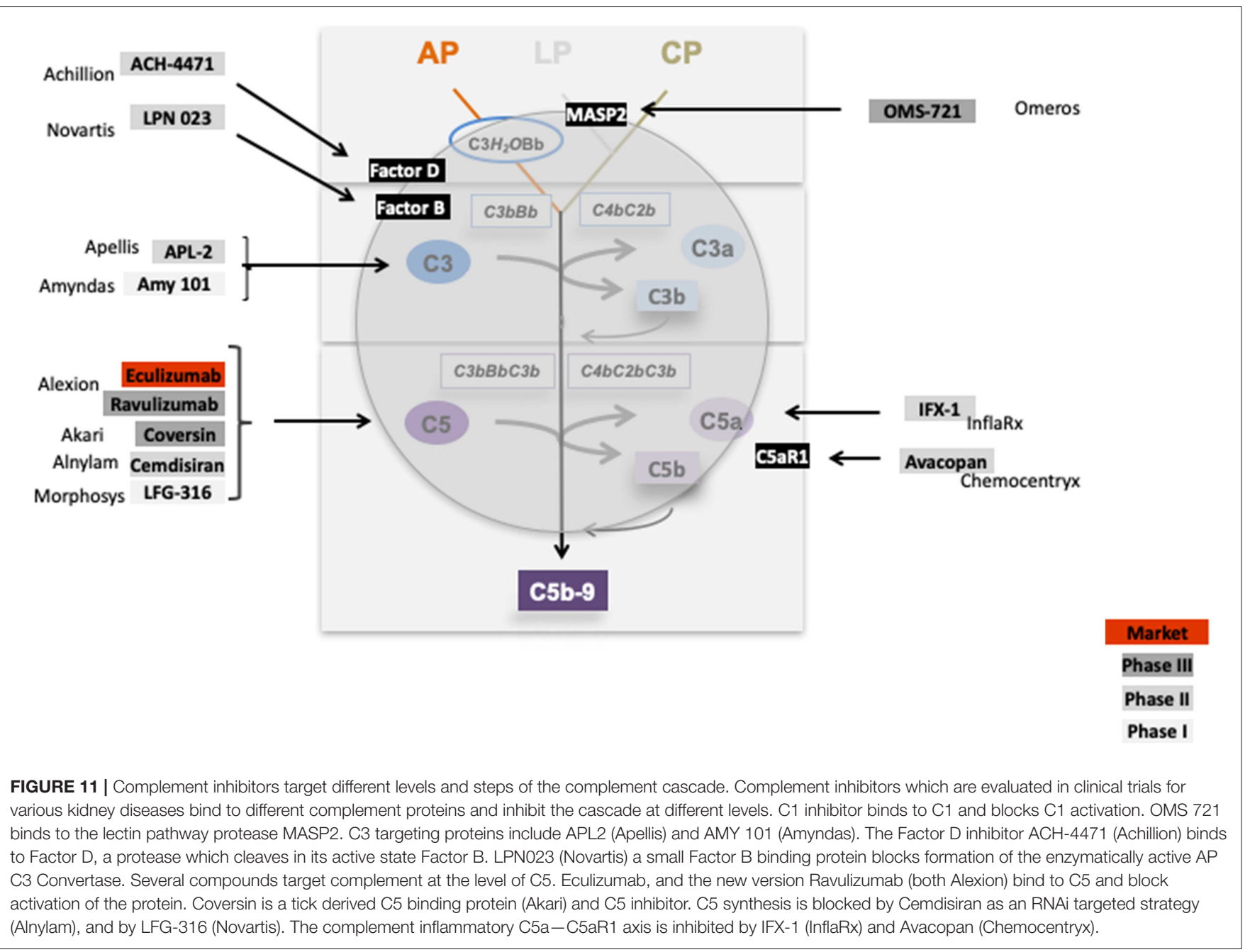

regulatory loops, regulatory networks and feedback pathways of the complement cascade, as well as the crosstalk with other immune systems like the coagulation cascade will allow to use the inhibitors for the clear benefit of the patient. It will be of interest to see which of the various inhibitors is most effective for the outlined renal diseases and given the heterogeneity of the diseases and their existing subforms it will be of interest to evaluate the different causes and responses of the inhibitors. In total, many clinical trials and the emerging list of additional new inhibitors show that complement inhibition in glomerular diseases has a very promising future.

\section{REFERENCES}

1. Zipfel PF, Skerka C. Complement regulators and inhibitory proteins. Nat Rev Immunol. (2009) 9:729-40. doi: 10.1038/nri2620

2. Hajishengallis G, Reis ES, Mastellos DC, Ricklin D, Lambris JD. Novel mechanisms and functions of complement. Nat Immunol. (2017) 18:1288-98. doi: $10.1038 /$ ni.3858

3. McCullough JW, Renner B, Thurman JM. The role of the complement system in acute kidney injury. Semin Nephrol. (2013) 33:543-56. doi: 10.1016/j.semnephrol.2013.08.005

\section{AUTHOR CONTRIBUTIONS}

PZ, TW, and CS designed the concept and planned the work. RR, SA, and FP performed the work. All authors wrote the manuscript.

\section{FUNDING}

This work of the authors were supported by the Collaborative Research Center (CRC) SFB 1192 by the Deutsche Forschungsgemeinschaft (DFG), project B6.

4. Groopman EE, Rasouly HM, Gharavi AG. Genomic medicine for kidney disease. Nat Rev Nephrol. (2017) 14:83-104. doi: 10.1038/nrneph.2017.167

5. Bomback AS, Markowitz GS, Appel GB. Complement-mediated glomerular diseases: a tale of 3 pathways. Kidney Int Rep. (2016) 1:148-55. doi: 10.1016/j.ekir.2016.06.005

6. Holers VM. Complement and its receptors: new insights into human disease. Annu Rev Immunol. (2014) 32:433-59. doi: 10.1146/annurev-immunol-032713-120154

7. Yaseen S, Demopulos G, Dudler T, Yabuki M, Wood CL, Cummings WJ, et al. Lectin pathway effector enzyme mannan-binding lectin-associated serine 
protease-2 can activate native complement C3 in absence of $\mathrm{C} 4$ and/or C2. FASEB J. (2017) 31:2210-9. doi: 10.1096/fj.201601306R

8. Coulthard LG, Woodruff TM. Is the complement activation product C3a a proinflammatory molecule? Re-evaluating the evidence and the myth. J Immunol. (2015) 194:3542-8. doi: 10.4049/jimmunol. 1403068

9. Pedersen DV, Roumenina L, Jensen RK, Gadeberg TA, Marinozzi C, Picard $\mathrm{C}$, et al. Functional and structural insight into properdin control of complement alternative pathway amplification. EMBO J. (2017) 36:1084-99. doi: 10.15252/embj.201696173

10. Laumonnier Y, Karsten CM, Köhl J. Novel insights into the expression pattern of anaphylatoxin receptors in mice and men. Mol Immunol. (2017) 89:44-58. doi: 10.1016/j.molimm.2017.05.019

11. Wang H, Ricklin D, Lambris JD. Complement-activation fragment C4a mediates effector functions by binding as untethered agonist to proteaseactivated receptors 1 and 4. Proc Natl Acad Sci USA. (2017) 114:10948-53. doi: 10.1073/pnas.1707364114

12. Irmscher S, Brix S, Zipfel SLH, Halder LD, Mutlutürk S, Wulf S, et al. Serum FHR1 binding to necrotic-type cells activates monocytic inflammasome and marks necrosic sites in vasculopathies. Nat Commun. (2019) 10:2961. doi: 10.1038/s41467-019-10766-0

13. Noris M, Mescia F, Remuzzi G. STEC-HUS, atypical HUS and TTP are all diseases of complement activation. Nat Rev Nephrol. (2012) 8:622-33. doi: 10.1038/nrneph.2012.195

14. Nester CM, Barbour T, de Cordoba SR, Dragon-Durey MA, Fremeaux-Bacchi V, Goodship TH, et al. Atypical aHUS: state of the art. Mol Immunol. (2015) 67:31-42. doi: 10.1016/j.molimm.2015.03.246

15. Szilágyi A, Kiss N, Bereczki C, Tálosi G, Rácz K, Túri S, et al. The role of complement in Streptococcus pneumoniae-associated haemolytic uraemic syndrome. Nephrol Dial Transplant. (2013) 28:2237-45. doi: $10.1093 / \mathrm{ndt} / \mathrm{gft} 198$

16. Goodship TH, Cook HT, Fakhouri F, Fervenza FC, Frémeaux-Bacchi V, Kavanagh D, et al. Atypical hemolytic uremic syndrome and C3 glomerulopathy: conclusions from a "Kidney Disease: Improving Global Outcomes” (KDIGO) Controversies Conference. Kidney Int. (2017) 91:53951. doi: 10.1016/j.kint.2016.10.005

17. Karpman D, Loos S, Tati R, Arvidsson I. Haemolytic uraemic syndrome. J Intern Med. (2017) 281:123-48. doi: 10.1111/joim.12546

18. Noris M, Caprioli J, Bresin E, Mossali C, Pianetti G, Gamba S, et al. Relative role of genetic complement abnormalities in sporadic and familial aHUS and their impact on clinical phenotype. Clin J Am Soc Nephrol. (2010) 5:1844-59. doi: 10.2215/CJN.02210310

19. Lemaire M, Frémeaux-Bacchi V, Schaefer F, Choi M, Tang WH, Le Quintrec $M$, et al. Recessive mutations in DGKE cause atypical hemolytic-uremic syndrome. Nat Genet. (2013) 45:531-6. doi: 10.1038/ ng. 2590

20. Zipfel PF, Edey M, Heinen S, Józsi M, Richter H, Misselwitz J, et al. Deletion of complement Factor H-related genes CFHR1 and CFHR3 is associated with atypical hemolytic uremic syndrome. PLoS Genet. (2007) 3:e41. doi: 10.1371/journal.pgen.0030041

21. Durey MA, Sinha A, Togarsimalemath SK, Bagga A. Anti-complementFactor H-associated glomerulopathies. Nat Rev Nephrol. (2016) 12:563-78. doi: 10.1038/nrneph.2016.99

22. Legendre CM, Licht C, Loirat C. Eculizumab in atypical hemolyticuremic syndrome. N Engl J Med. (2013) 369:1379-80. doi: 10.1056/NEJM13 08826

23. Legendre CM, Licht C, Muus P, Greenbaum LA, Babu S, Bedrosian C, et al. Terminal complement inhibitor eculizumab in atypical hemolyticuremic syndrome. $N$ Engl J Med. (2013) 368:2169-81. doi: 10.1056/NEJMoa 1208981

24. Hillmen P, Muus P, Röth A, Elebute MO, Risitano AM, Schrezenmeier H, et al. Long-term safety and efficacy of sustained eculizumab treatment in patients with paroxysmal nocturnal haemoglobinuria. Br J Haematol. (2013) 162:62-73. doi: 10.1111/bjh.12347

25. Sheridan D, Yu ZX, Zhang Y, Patel R, Sun F, Lasaro MA, et al. Design and preclinical characterization of ALXN1210: a novel anti-C5 antibody with extended duration of action. PLoS ONE. (2018) 13:e0195909. doi: 10.1371/journal.pone.0195909
26. Nishimura J, Yamamoto M, Hayashi S, Ohyashiki K, Ando K, Brodsky AL, et al. Genetic variants in C5 and poor response to eculizumab. $N$ Engl J Med. (2014) 370:632-9. doi: 10.1056/NEJMoa1311084

27. Brogan P, Eleftheriou D. Vasculitis update: pathogenesis and biomarkers. Pediatr Nephrol. (2018) 33:187-98. doi: 10.1007/s00467-017-3597-4

28. Wester Trejo MAC, Trouw LA, Bajema IM. The role of complement in antineutrophil cytoplasmic antibody-associated vasculitis. Curr Opin Rheumatol. (2019) 31:3-8. doi: 10.1097/BOR.0000000000000557

29. Pickering MC, D'Agati VD, Nester CM, Smith RJ, Haas M, Appel GB, et al. C3 glomerulopathy: consensus report. Kidney Int. (2013) 84:1079-89. doi: $10.1038 / \mathrm{ki} .2013 .377$

30. Zipfel PF, Skerka C, Chen Q, Wiech T, Goodship T, Johnson S, et al. The role of complement in C3 Glomerulopathy. Mol Immunol. (2015) 67:21-30. doi: 10.1016/j.molimm.2015.03.012

31. Abrera-Abeleda MA, Nishimura C, Smith JL, Sethi S, McRae JL, Murphy $\mathrm{BF}$, et al. Variations in the complement regulatory genes Factor $\mathrm{H}(\mathrm{CFH})$ and Factor H related 5 (CFHR5) are associated with membranoproliferative glomerulonephritis type II (dense deposit disease). J Med Genet. (2006) 43:582-9. doi: 10.1136/jmg.2005.038315

32. Sethi S, Fervenza FC. Membranoproliferative glomerulonephritisa new look at an old entity. N Engl J Med. (2012) 366:1119-31. doi: 10.1056/NEJMra1108178

33. Vasilev VV, Radanova M, Lazarov VJ, Dragon-Durey MA, FremeauxBacchi V, Roumenina LT. Autoantibodies against C3b-functional consequences and disease relevance. Front Immunol. (2019) 10:64. doi: 10.3389/fimmu.2019.00064

34. Donadelli R, Pulieri P, Piras R, Iatropoulos P, Valoti E, Benigni A, et al. Unraveling the molecular mechanisms underlying complement dysregulation by nephritic factors in C3G and IC-MPGN. Front Immunol. (2018) 9:2329. doi: 10.3389/fimmu.2018.02329

35. Zhao F, Afonso S, Lindner S, Hartmann A, Löschmann I, Nilsson B, et al. C3-Glomerulopathy autoantibodies mediate distinct effects on complement C3- and C5 -convertases. Front Immunol. (2019) 10:1030. doi: 10.3389/fimmu.2019.01030

36. Radhakrishnan S, Lunn A, Kirschfink M, Thorner P, Hebert D, Langlois V, et al. Eculizumab and refractory membranoproliferative glomerulonephritis. $N$ Engl J Med. (2012) 366:1165-6. doi: 10.1056/NEJMc1106619

37. Bomback AS, Smith RJ, Barile GR, Zhang Y, Heher EC, Herlitz L, et al. Eculizumab for dense deposit disease and C3 glomerulonephritis. Clin J Am Soc Nephrol. (2012) 7:748-56. doi: 10.2215/CJN.12901211

38. Le Quintrec M, Lapeyraque AL, Lionet A, Sellier-Leclerc AL, Delmas $\mathrm{Y}$, Baudouin V, et al. Patterns of clinical response to eculizumab in patients with C3 glomerulopathy. Am J Kidney Dis. (2018) 72:84-92. doi: 10.1053/j.ajkd.2017.11.019

39. Gharavi AG, Kiryluk K, Choi M, Li Y, Hou P, Xie J, et al. Genome-wide association study identifies susceptibility loci for IgA nephropathy. Nat Genet. (2011) 43:321-7. doi: 10.1038/ng.787

40. Rodrigues JC, Haas M, Reich HN. IgA nephropathy. Clin J Am Soc Nephrol. (2017) 12:677-86. doi: 10.2215/CJN.07420716

41. Floege J, Daha MR. IgA nephropathy: new insights into the role of complement. Kidney Int. (2018) 94:16-8. doi: 10.1016/j.kint.2018.03.009

42. Rollino C, Vischini G, Coppo R. IgA nephropathy and infections. J Nephrol. (2016) 29:463-8. doi: 10.1007/s40620-016-0265-x

43. Floege J, Rauen T. Glomerular disease: immunosuppressant-induced reduction of proteinuria in IgAN. Nat Rev Nephrol. (2016) 12:380-2. doi: $10.1038 /$ nrneph.2016.84

44. Zhu L, Zhai YL, Wang FM, Hou P, Lv JC, Xu DM, et al. Variants in complement factor $\mathrm{H}$ and complement factor $\mathrm{H}$-related protein genes, CFHR3 and CFHR1, affect complement activation in IgA nephropathy. J Am Soc Nephrol. (2015) 26:1195-04. doi: 10.1681/ASN.2014010096

45. Xie J, Kiryluk K, Li Y, Mladkova N, Zhu L, Hou P, et al. Fine mapping implicates a deletion of CFHR1 and CFHR3 in protection from IgA nephropathy in Han Chinese. J Am Soc Nephrol. (2016) 27:3187-94. doi: 10.1681/ASN.2015111210

46. Merinero HM, García SP, García-Fernández J, Arjona E, Tortajada A, Rodríguez de Córdoba S. Complete functional characterization of diseaseassociated genetic variants in the complement factor $\mathrm{H}$ gene. Kidney Int. (2018) 93:470-81. doi: 10.1016/j.kint.2017.07.015 
47. Zhu L, Guo WY, Shi SF, Liu LJ, Lv JC, Medjeral-Thomas NR, et al. Circulating complement factor $\mathrm{H}$-related protein 5 levels contribute to development and progression of IgA nephropathy. Kidney Int. (2018) 94:1508. doi: 10.1016/j.kint.2018.02.023

48. Medjeral-Thomas NR, Lomax-Browne HJ, Beckwith H, Willicombe M, McLean AG, Brookes P, et al. Circulating complement factor H-related proteins 1 and 5 correlate with disease activity in IgA nephropathy. Kidney Int. (2017) 92:942-52. doi: 10.1016/j.kint.2017.03.043

49. Thurman JM, Laskowski J. Complement Factor H-related proteins in IgA nephropathy-sometimes a gentle nudge does the trick. Kidney Int. (2017) 92:790-3. doi: 10.1016/j.kint.2017.05.025

50. Jullien P, Laurent B, Claisse G, Masson I, Dinic M, Thibaudin D, et al. Deletion variants of CFHR1 and CFHR3 associate with mesangial immune deposits but not with progression of IgA nephropathy. J Am Soc Nephrol. (2018) 29:661-9. doi: 10.1681/ASN.2017010019

51. Zhai YL, Meng SJ, Zhu L, Shi SF, Wang SX, Liu LJ, et al. Rare variants in the complement Factor H-related protein 5 gene contribute to genetic susceptibility to IgA nephropathy. J Am Soc Nephrol. (2016) 27:2894-05. doi: 10.1681/ASN.2015010012

52. Leffers HCB, Lange T, Collins C, Ulff-Møller CJ, Jacobsen S. The study of interactions between genome and exposome in the development of systemic lupus erythematosus. Autoimmun Rev. (2019) 18:382-92. doi: 10.1016/j.autrev.2018.11.005

53. Felten R, Sagez F, Gavand PE, Martin T, Korganow AS, Sordet C, et al. 10 most important contemporary challenges in the management of SLE. Lupus Sci Med. (2019) 6:e000303. doi: 10.1136/lupus-2018-0 00303

54. Zhao J, Wu H, Khosravi M, Cui H, Qian X, Kelly JA, et al. Association of genetic variants in complement Factor $\mathrm{H}$ and Factor $\mathrm{H}$ related genes with systemic lupus erythematosus susceptibility. PLoS Genet. (2011) 7:e1002079. doi: 10.1371/journal.pgen.1002079

55. Holmes LV, Strain L, Staniforth SJ, Moore I, Marchbank K, Kavanagh $\mathrm{D}$, et al. Determining the population frequency of the CFHR3/CFHR1 deletion at 1q32. PLoS ONE. (2013) 8:e60352. doi: 10.1371/journal.pone. 0060352

56. Hoxha E, Stahl RAK. Translational aspects of primary membranous nephropathy. Semin Nephrol. (2017) 37:436-46. doi: 10.1016/j.semnephrol.2017.05.017

57. Couser WG. Primary membranous nephropathy. Clin J Am Soc Nephrol. (2017) 12:983-97. doi: 10.2215/CJN.11761116

58. Hoxha E, Thiele I, Zahner G, Panzer U, Harendza S, Stahl RA. Phospholipase A2 receptor autoantibodies and clinical outcome in patients with primary membranous nephropathy. J Am Soc Nephrol. (2014) 25:135766. doi: 10.1681/ASN.2013040430

59. Meyer-Schwesinger C, Lambeau G, Stahl RA. Thrombospondin type-1 domain-containing 7A in idiopathic membranous nephropathy. N Engl J Med. (2015) 372:1074-5. doi: 10.1056/NEJMc1500130
60. Tomas NM, Beck LH Jr, Meyer-Schwesinger C, Seitz-Polski B, Ma $\mathrm{H}$, Zahner G, et al. Thrombospondin type-1 domain-containing 7A in idiopathic membranous nephropathy. N Engl J Med. (2014) 371:2277-87. doi: 10.1056/NEJMoa1409354

61. von Haxthausen F, Reinhard L, Pinnschmidt HO, Rink M, Soave A, Hoxha E, et al. Antigen-specific IgG subclasses in primary and malignancy-associated membranous nephropathy. Front. Immunol. (2018) 9:3035. doi: 10.3389/fimmu.2018.03035

62. Tomas NM, Hoxha E, Reinicke AT, Fester L, Helmchen U, Gerth J, et al. Autoantibodies against thrombospondin type 1 domain-containing 7A induce membranous nephropathy. J Clin Invest. (2016) 126:2519-32. doi: 10.1172/JCI85265

63. Seikrit C, Ronco P, Debiec H. Factor H autoantibodies and membranous nephropathy. N Engl J Med. (2018) 379:2479-81. doi: 10.1056/NEJMc1805857

64. Prodinger WM, Hellwage J, Spruth M, Dierich MP, Zipfel PF. The C-terminus of factor $\mathrm{H}$ : monoclonal antibodies inhibit heparin binding and identify epitopes common to factor $\mathrm{H}$ and factor H-related proteins. Biochem J. (1998) 331(Pt 1):41-7. doi: 10.1042/bj3310041

65. Józsi M, Oppermann M, Lambris JD, Zipfel PF. The C-terminus of complement factor $\mathrm{H}$ is essential for host cell protection. Mol Immunol. (2007) 44:2697-706. doi: 10.1016/j.molimm.2006.12.001

66. Nauser CL, Farrar CA, Sacks SH. Complement recognition pathways in renal transplantation. J Am Soc Nephrol. (2017) 28:2571-8. doi: 10.1681/ASN.2017010079

67. Sanghera P, Ghanta M, Ozay F, Ariyamuthu VK, Tanriover B. Kidney diseases associated with alternative complement pathway dysregulation and potential treatment options. Am J Med Sci. (2017) 354:533-8. doi: 10.1016/j.amjms.2017.03.024

68. Hu C, Li L, Ding P, Li L, Ge X, Zheng L, et al. Complement inhibitor CRIg/FH ameliorates renal ischemia reperfusion injury via activation of PI3K/AKT signaling. J Immunol. (2018) 201:3717-30. doi: 10.4049/jimmunol.1800987

69. Danobeitia JS, Ziemelis M, Ma X, Zitur LJ, Zens T, Chlebeck PJ, et al. Complement inhibition attenuates acute kidney injury after ischemiareperfusion and limits progression to renal fibrosis in mice. PLoS ONE. (2017) 12:e0183701. doi: 10.1371/journal.pone.0183701

Conflict of Interest Statement: The authors declare that the research was conducted in the absence of any commercial or financial relationships that could be construed as a potential conflict of interest.

Copyright (c) 2019 Zipfel, Wiech, Rudnick, Afonso, Person and Skerka. This is an open-access article distributed under the terms of the Creative Commons Attribution License (CC BY). The use, distribution or reproduction in other forums is permitted, provided the original author(s) and the copyright owner(s) are credited and that the original publication in this journal is cited, in accordance with accepted academic practice. No use, distribution or reproduction is permitted which does not comply with these terms. 